BMJ Nutrition, Prevention \& Health

\title{
Zinc as nutritional intervention and prevention measure for COVID-19 disease
}

\author{
J P Mossink
}

To cite: Mossink JP. Zinc as nutritional intervention and prevention measure for COVID-19 disease. BMJ Nutrition, Prevention \& Health 2020;3:e000095. doi:10.1136/ bmjnph-2020-000095

LymeCenter, Amersfoort, Utrecht, Netherlands

Correspondence to Dr J P Mossink, Amersfoort, Utrecht, Netherlands; mossink@lymecenter.nl

Received 27 April 2020 Revised 17 May 2020 Accepted 19 May 2020 Published Online First 17 June 2020
Check for updates

(C) Author(s) (or their employer(s)) 2020. Re-use permitted under CC BY-NC. No commercial re-use. See rights and permissions. Published by BMJ.

\section{ABSTRACT}

The present spread of severe acute respiratory syndrome coronavirus 2, provoking COVID-19 disease, progresses rapidly worldwide. In current absence of a curative treatment and an effective, safe vaccine, there is a pressing need to focus on identifying and correcting deficits in immune function in order to reduce risk of severe progress of the disease and to lower the number of infections and fatalities. This paper evaluates the most recent literature on zinc status related to antiviral immunity and its possible role in COVID-19. It is concluded that zinc is a critical factor for antiviral immunity. There is ample evidence suggesting that zinc depletion, also prevalent in high-income nations, compromises immune functions. Notably, major risk groups for COVID-19, the elderly, men more than women, obese individuals and patients with diabetes are all at risk of zinc deficiency. Moreover, various widely used antihypertensive drugs and statin therapy have been reported to negatively influence zinc status. As zinc depletion impairs antiviral immunity, it is hypothesised to increase susceptibility for COVID-19. Therefore, dietary preventive measures and prompt implementation of zinc supplementation for risk groups should be considered. Large-scale studies are urgently needed to investigate the role of micronutrients and antiviral immunity, in particular drug-micronutrient immunity interaction.

\section{INTRODUCTION}

The current spread of severe acute respiratory syndrome coronavirus 2 (SARS-CoV2), provoking COVID-19 disease, progresses rapidly thereby urgently challenging the healthcare system worldwide. In the absence of curative treatment as well as an effective and safe vaccine at the moment, there is a pressing need to focus on identifying and correcting deficits in immune function, especially for those at risk for COVID-19. The elderly and people with comorbid conditions show increased risk of severe progression. Zinc status, known to be a critical factor for antiviral immune response, ${ }^{2-4}$ may have the potential to influence the course of the viral infection in individuals. Here, it is argued that particularly adult populations at risk of disturbed zinc homeostasis have increased risk of severe progression of COVID-19.
Moreover, nutritional, immunological and clinical data suggest that zinc status may play a pivotal role in preventing and controlling COVID-19 disease. This opens up possibilities for targeted dietary preventive and nutritional intervention measures to improve antiviral immune response.

\section{Zinc in antiviral immunity}

Zinc is involved in generating innate as well as acquired antiviral immune response..$^{2-6}$ First of all, zinc is essential for the barrier function of mucosal epithelium due to its antioxidant and anti-inflammatory activity. It also regulates tight junction proteins that are important for the maintenance of mucosal membrane integrity. ${ }^{57}$ Reduction of mucosal integrity and loss of tight junction cohesion aggravates viral inflammation. These deteriorations result in alveolar oedema, due to leakage of high weight proteins and water, resulting in acute respiratory distress syndrome. ${ }^{7}$

Proliferation, differentiation, maturation and functioning of leucocytes including lymphocytes are all regulated by zinc. ${ }^{7}$ Zinc ions regulate intracellular signalling pathways in both innate and adaptive immune cells. Hereby zinc acts directly by binding reversibly to regulating proteins or indirectly by modulating enzymes, such as phosphates, involved in signalling pathways. Production of reactive oxygen species (ROS) and cytokines depend on zinc availability. ${ }^{36}$ ROS production is required for intracellular killing of pathogens as well as for the formation of neutrophil extracellular traps, released by granulocytes to neutralise pathogens. ${ }^{36}$ Zinc treatment in vitro has demonstrated to increase interferon $\alpha$ (IFN $\alpha)$ production by leukocytes, enhancing its antiviral activity. ${ }^{7}$

Due to involvement of zinc in various immune functions, zinc deficiency results in:

- Reduced activity of immune cells like impaired phagocytosis. $^{389}$

- Decreased critical neutrophil functions. ${ }^{389}$ 
- Weakened natural killer cell function. ${ }^{389}$

- Reduced lymphocyte number and activation. ${ }^{35}$

- Diminished antibody production. ${ }^{6}$

- Imbalanced T helper cells cytokine secretion with decreased IFN $\gamma$ production. ${ }^{6}{ }^{10}$ IFNs are immunostimulatory cytokines with antiviral activity. ${ }^{2}$

- Increased thymic atrophy and consequent risk of infection. ${ }^{5}$

On the other hand, excess of zinc can also impair immune response by inhibiting T-lymphocyte and Blymphocyte function, reducing intracellular pathogen destruction in macrophages or inducing an overload of regulatory T-cells. ${ }^{3611}$ This demonstrates that a balanced zinc homeostasis is critical for adequate immune functions.

Furthermore, accurate modulation of theinflammatory response is required for achieving an adequate antiviral immune response. ${ }^{6}$ Hereby, zinc is crucial to counteract excessive inflammatory reactions by improving control of regulatory transcriptional factor, nuclear factor$\kappa \mathrm{B}(\mathrm{NF}-\kappa \mathrm{B})$, resulting in a reduced production of pro-inflammatory cytokines. ${ }^{3} 4 \quad 7 \quad 8 \quad$ Zinc signals can increase intracellular levels of zinc finger protein A20, which inhibits activation of $\mathrm{NF}-\kappa \mathrm{B}$ through a negative feedback loop, downregulating proinflammatory factors as well. ${ }^{3610}$ Zinc may also limit excessive inflammatory response by modulating regulatory $\mathrm{T}-$ cell functions. ${ }^{7}$

Moreover, zinc has proven direct antiviral activity towards a wide variety of viruses ${ }^{2}{ }^{3}$; enhancing antiviral immunity. Zinc deficiency results in a compromised immune system along with reduced zinc availability for direct antiviral action, increasing susceptibility for viral infections. ${ }^{258912}$ Hence, zinc-deficient populations are more likely to acquire pneumonia ${ }^{5713}$ and viral infections as documented for hepatitis $\mathrm{C}$ and $\mathrm{HIV}^{2}$ Some studies suggest that zinc may also improve antibacterial immune response to Streptococcus Pneumoniae, which can provoke coinfection in viral pneumonia. ${ }^{27}$ In addition, the antiinflammatory effects of zinc also aid to limit tissue damage in case of pneumonia and decrease the risk of sepsis. ${ }^{37}$

The increased knowledge about the role of zinc in viral immunity has resulted in clinical studies, showing evident therapeutic effect of zinc supplementation in viral infections like common cold ${ }^{7}$ and herpes simplex. ${ }^{23}$ Presently, zinc is recommended by WHO as first-line treatment, with oral rehydration solution, for acute gastroenteritis in children because of its clinically proven efficacy to reduce diarrhoea. ${ }^{14}$ The question is to what extent zinc is also involved in antiviral immunity in case of COVID-19.

\section{Who are at risk of zinc deficiency?}

Emerging characteristics regarding COVID-19 show that patients most at risk of fatal outcome of COVID-19 are the elderly, those with cardiovascular disease, diabetes, chronic respiratory disease, hypertension, overweight and cancer. Male show increased risk compared with female. ${ }^{1516}$ Comparing these outcomes to the risk groups for low zinc status then the following can be noticed: the elderly population, more at risk of severe COVID-19 disease, ${ }^{15}$ is also more at risk of zinc deficiency. $^{2} 31112$ A cross-sectional population survey among a random sample of elder participants, aged 67-87 years, found $10.1 \%$ zinc deficient, in line with previous studies. The prevalence was significantly higher as age increased and notably more men $(13.1 \%)$ than women $(7.3 \%)$ were zinc depleted. ${ }^{17} \mathrm{~A}$ zinc-poor diet, increased alcoholintake and disease-state can all contribute to zinc depletion. $^{2} 17$

Concerning diabetes, a meta-analysis including 52 studies on micronutrients in diabetes demonstrated significantly lower zinc status for patients with diabetes $(n=20183)$ compared with controls. ${ }^{18}$ The results of this study are consistent with other studies that observed zinc depletion in up to $77 \%$ of patients with type 2 diabetes ${ }^{19-21}$ or found an inverse correlation between blood glucose and zinc levels. ${ }^{22}$ Furthermore, research demonstrates that obesity predisposes for zinc deficiency. Studies have revealed reduced serum zinc levels in up to $28 \%$ of obese individuals prior to bariatric surgery and in 36\%-51\% of patients afterwards. Another study in Spain among 115 morbid obese women found $74 \%$ of them zinc deficient. ${ }^{23}$ In conclusion, these studies suggest a strong correlation between age, diabetes, overweight and zinc status.

\section{Drug use and zinc balance}

For most of the comorbid groups affected by COVID-19, we may assume that they include a relative high percentage of vulnerable patients with serious cardiovascular or respiratory dysfunction. Therefore, these patients clearly are at risk of severe COVID-19 disease. However, the relative high percentage of patients with hypertension struck by fatal outcome is striking: the in China reported case fatality rate for the hypertension group $(6.0 \%)$ is nearly as high as for the chronic lung disease group $(6.3 \%) .{ }^{1}$ The high risk for hypertensive patients is difficult to explain solely by their pathological condition, considering hypertension in itself appears not directly associated with compromised immune functions, unless it is accompanied by organ damage, like kidney failure. Thus, it seems likely that other factors are involved. Unfortunately, data on the clinical characteristics of the risk groups as well as their prognostic factors are limited as the pandemic is still in progress.

An important issue is the use of antihypertensive pharmaceuticals and their possible effect on immune functions. With regard to zinc, various antihypertensive drugs have been reported to negatively influence zinc balance, resulting in a potentially reduced antiviral immune response.

First, thiazide diuretics, widely used in hypertensive therapy, can result in significantly increased urinary zinc excretion ${ }^{24-26}$ and consequently reduce tissue zinc concentrations. ${ }^{26}$ A study on the long-term use of hydrochlorothiazide ( $\geq 6$ months) resulted in significant lower serum zinc levels in 20 out of 39 subjects when compared with controls. ${ }^{24}$ Patients with hypertension $(n=36)$ on 
monotherapy with diuretics, most of them using thiazidelike diuretics, were found to have significant lower zinc concentration in serum and erythrocytes after 3 months of therapy when compared with baseline levels in a randomised trial. ${ }^{25}$

Furthermore, long-term use of some ACE-inhibitors like captopril (50-150 mg/day), verapamil (240 mg/ day) and ramipril (5mg/day) can significantly lower serum zinc levels. ${ }^{24}$ Serum zinc concentrations were also decreased in subjects $(n=14)$ after using ACE-inhibitors for 3 months. In this study, dietary zinc intake was controlled during the test period. In the same study, a significant decrease of erythrocyte zinc concentration was also observed in patients with hypertension $(n=18)$ on calcium antagonists $(\mathrm{Ca} \text {-antagonists })^{25}$ in contrast to a previous study $(n=20)$ in which no such changes were found. However, dietary zinc intake monitoring was not reported. ${ }^{24}$

In addition, some angiotensin 2 receptor blockers (ARBs) proved to have a potential to lower zinc levels as well. A 3-month treatment with valsartan $(80 \mathrm{mg} /$ day $)$ has revealed to reduce serum zinc and erythrocyte zinc levels significantly in hypertensive patients. Stand-alone therapy with losartan $(50.0 \mathrm{mg} /$ day $)$ in 17 hypertensive patients for 4 weeks resulted in significantly increased urinary zinc excretion and zinc depletion. ${ }^{24}$ However, no alterations in serum and erythrocyte zinc level were found in 12 patients with hypertension after 3 months of treatment with ARBs, although drug dosages were not reported. ${ }^{24}$ Meanwhile, studies done on beta-blockers remain inconclusive about their effect on zinc metabolism. 24252728

It should be noted that most of the studies on antihypertensive drugs and zinc status lasted between 4 weeks and 6 months. That is considerably shorter than the actual situation in which hypertensive patients usually take these drugs for years. Moreover, mainly monotherapy was investigated, while in medical practice the use of two or more antihypertensive drugs is often applied. One drug could have an additive effect on the other drug in lowering zinc levels as was shown for the combination losartan $(50.0 \mathrm{mg} /$ day $) /$ hydrochlorothiazide $(12.5 \mathrm{mg} /$ day $){ }^{24}$

Moreover diuretics, ACE inhibitors, ARBs and $\mathrm{Ca}-$ antagonists are also extensively used for other cardiovascular disorders, either separate or combined with additional drugs. For instance, statins are widely used for treating dyslipidaemia in cardiovascular disease. Longterm statin therapy is associated with $10 \%-45 \%$ higher risk for new-onset type 2 diabetes,${ }^{29}$ which can induce zinc depletion. Hence, many cardiovascular patients using antihypertensives or statins, which can affect zinc balance, ${ }^{3031}$ may be at increased risk of zinc deficiency (table 1). For numerous other cardiovascular drugs, sufficient data on zinc metabolism are lacking.

\section{Zinc and susceptibility for COVID-19}

The decline of immune functions with ageing, which is often referred to as 'immunosenescence', appears to be related to lower zinc availability. ${ }^{6} 91112$ Mild zinc deficiency, commonly seen with ageing, leads to dysregulation of the adaptive immune system decreasing the specific immune response (B-cell function, production of immunoglobulins) along with the tendency of enhanced production of proinflammatory cytokines, called 'inflammaging'. In chronic inflammation, there is a continuous sequestration of intracellular zinc and the release of zinc bound to intracellular proteins (metallothioneins) is impeded. As a consequence, intracellular zinc ion bioavailability, indispensable for proper immune function, is reduced. ${ }^{6} 10$ Zinc supplementation partially restores these alterations. ${ }^{5681012}$ Moreover, inflammaging often seen with ageing can affect innate immunity as well. Especially in the early stage of newly acquired viral infections an adequate immune response depends largely on the innate immune system. In particular zinc is critical for its efficient functioning. ${ }^{58}$ In COVID-19, there are strong indications for downregulation of the innate immune response along with a high inflammatory condition, features similar to those found in SARS and Middle East respiratory syndrome. This may explain why elderly are more at risk of COVID-19 in contrast to young children who benefit from a highly effective innate immune response. $^{32}$

Apart from its role in immune functions, zinc has also shown direct antiviral activity for a number of RNA viruses. It was demonstrated that zinc efficiently inhibits the replication of SARS-CoV in cell culture, showing the crucial role of intracellular zinc in inhibiting replication of the virus. ${ }^{33}$ This study by te Velthuis et al used the zinc ionophore pyrithione, which transports zinc ions in large amounts from the extracellular matrix into the cell, in order to increase intracellular zinc levels. Without zinc, the ionophore was unable to effectively inhibit viral replication. The pharmaceuticals chloroquine and hydroxychloroquine, also known to function as zinc ionophores, are now being tested in several clinical studies for the treatment of COVID-19, although without simultaneous supplementation of zinc. The antiviral properties of these drugs or other zinc ionophores could depend on the availability of zinc, which illustrates that the combination with zinc supplementation could be useful to improve their therapeutic effect in patients with COVID-19. ${ }^{34}$

In addition papain-like protein 2 , a viral protease of SARS-CoV that is fundamental for its virulence, was potently inhibited by zinc. ${ }^{35}$ The same viral inhibiting actions of zinc found for SARS-CoV may also apply to SARS-CoV2, since their genome is similar. In case zinc might have direct antiviral activity towards SARS-CoV2, then zinc status will be of an even greater importance to reduce the viral load in COVID-19.

Only a small functional zinc reserve, located in the liver and other tissues, is available to the human body for rapid exchange with the plasma, enough for just a few days. Hence, a systemic increased demand of zinc, increased excretion, low intake or impaired absorption due to disease inevitably results into zinc deficiency. ${ }^{6} 8111224$ 
Table 1 The table describes the findings, reported in studies, regarding serum zinc concentration and intracellular zinc concentration related to the risk factors for COVID-19 (including age, type 2 diabetes and obesity), antihypertensive agents as well as statin therapy

\begin{tabular}{|c|c|c|c|}
\hline Type of study & $\begin{array}{l}n=\text { no of subjects } \\
N=\text { no of studies }\end{array}$ & Serum zinc concentration & $\begin{array}{l}\text { Intracellular zinc } \\
\text { concentration }\end{array}$ \\
\hline \multicolumn{4}{|l|}{ Increasing age } \\
\hline Observational $^{45}$ & $\mathrm{n}=853$ & $\downarrow$ in $31 \%$ of subjects & - \\
\hline Review $^{8}$ & $\mathrm{~N}=20$ & $\downarrow$ significant with increasing age & $\downarrow$ significant in 1 study \\
\hline Observational $^{17}$ & $n=1521$ & $\downarrow$ significant with increasing age & - \\
\hline Meta-analysis ${ }^{18}$ & $n=20183$ & $\downarrow$ significant versus control groups & - \\
\hline Cross-sectional $^{21}$ & $n=33$ & $\downarrow$ in $77 \%$ of the subjects & - \\
\hline Observational $^{19}$ & $n=31$ & $\downarrow$ in $27 \%$ versus control group $(n=31)$ & - \\
\hline
\end{tabular}

\section{Obesity}

$\begin{array}{lll}\text { Observational }^{23} & \mathrm{n}=115 & \downarrow \text { in } 74 \% \text { of subjects seeking bariatric }- \\ & & \text { surgery } \\ \text { Review }^{23} & \mathrm{~N}=3 & \downarrow \text { in } 28 \% \text { before bariatric surgery } \\ & & \downarrow \text { in } 36-51 \% \text { postbariatric surgery }\end{array}$

\section{Diuretics}

\begin{tabular}{|c|c|c|c|}
\hline Clinical Trial ${ }^{46}$ & Clopamide 5 mg/day, 16 weeks $(n=8)$ & $\downarrow$ significant versus baseline & $\uparrow$ in WBC, $\downarrow$ in RBC \\
\hline Clinical Trial ${ }^{47}$ & $\begin{array}{l}\text { Hydrochlorothiazide } 25-50 \mathrm{mg} \text { /day, } \\
6 \text { months }(\mathrm{n}=39)\end{array}$ & $\begin{array}{l}\downarrow \text { significant in } 51 \% \text { of treatment } \\
\text { group }\end{array}$ & - \\
\hline Clinical Trial ${ }^{48}$ & $\begin{array}{l}\text { Hydrochlorothiazide, } 25 \mathrm{mg}, \geq 3 \text { months } \\
(\mathrm{n}=9)\end{array}$ & $\leftrightarrow$ versus controls & - \\
\hline Clinical Trial ${ }^{\star 25}$ & $\begin{array}{l}\text { Indapamide }(n=29) \text {, Torasemide }(n=5) \text {, } \\
\text { Spironolacton }(n=2), 3 \text { months }\end{array}$ & $\begin{array}{l}\downarrow \text { significant compared with baseline } \\
\text { zinc level }\end{array}$ & $\begin{array}{l}\downarrow \text { significant compared with } \\
\text { baseline }\end{array}$ \\
\hline \multicolumn{4}{|l|}{ ACE-inhibitors } \\
\hline Clinical Trial ${ }^{49}$ & $\begin{array}{l}\text { Captopril, } 266 \pm 34 \mathrm{mg} / \text { day, } \\
>6 \text { months }(\mathrm{n}=11)\end{array}$ & $\downarrow$ significant versus baseline & - \\
\hline Clinical Trial ${ }^{50}$ & Captopril, 75 mg/day, $>3$ months $(n=6)$ & $\leftrightarrow$ versus other groups & $\downarrow$ significant versus baseline \\
\hline Clinical Trial $\dagger^{28}$ & $\begin{array}{l}\text { Captopril, } 50-150 \text { mg/day, } 6 \text { months, } \\
(n=10)\end{array}$ & $\downarrow$ significant versus baseline & $\leftrightarrow$ versus baseline \\
\hline Clinical Trial $\left.\right|^{51}$ & Captopril, 6 months $(n=16) \ddagger$ & $\leftrightarrow$ versus baseline & $\downarrow$ significant versus baseline \\
\hline Clinical Trial $\left.\right|^{51}$ & Enalapril, 6 months $(n=18) \ddagger$ & $\leftrightarrow$ versus baseline & $\downarrow$ significant versus baseline \\
\hline Clinical Trial ${ }^{50}$ & Enalapril, 20 mg/day, >3 months $(n=7)$ & $\leftrightarrow$ versus controls & $\leftrightarrow$ versus controls \\
\hline Clinical Trial $\dagger^{28}$ & Verapamil, 240 mg/day, 6 months $(n=10)$ & $\downarrow$ significant versus baseline & $\leftrightarrow$ versus baseline \\
\hline Clinical Trial $^{27}$ & Ramipril, 5 mg/day, 3 months $(n=20)$ & - & $\downarrow$ significant versus baseline \\
\hline Clinical Trial ${ }^{\star 25}$ & $\begin{array}{l}\text { Perindopril }(n=9) \text {, Captopril }(n=3) \text {, } \\
\text { Ramipril }(n=2), 3 \text { months }\end{array}$ & $\downarrow$ versus baseline & $\leftrightarrow$ versus baseline \\
\hline \multicolumn{4}{|c|}{ Calcium-antagonists } \\
\hline Clinical Trial ${ }^{\star 25}$ & $\begin{array}{l}\text { Amlodipine }(n=13) \text {, Nifedipine }(n=5) \text {, } \\
3 \text { months }\end{array}$ & $\leftrightarrow$ versus baseline & $\downarrow$ significant versus baseline \\
\hline Clinical Trial ${ }^{27}$ & Amlodipine, $10 \mathrm{mg} /$ day, 3 months $(n=20)$ & - & $\leftrightarrow$ versus baseline \\
\hline \multicolumn{4}{|c|}{ Angiotensin 2 receptor blockers } \\
\hline Clinical Trial ${ }^{27}$ & Valsartan, 80 mg/day, 3 months $(n=20)$ & $\downarrow$ significant versus baseline & $\downarrow$ significant versus baseline \\
\hline Clinical Trial $\ddagger^{52}$ & Losartan, 50 mg/day, 4 weeks $(n=17)$ & $\downarrow$ non-significant versus baseline & $\leftrightarrow$ versus baseline \\
\hline Clinical Trial ${ }^{\star 25}$ & $\begin{array}{l}\text { Losartan }(n=8), \text { Valsartan }(n=2) \text {, } \\
\text { Telmisartan }(n=2), 3 \text { months }\end{array}$ & $\leftrightarrow$ versus baseline & $\leftrightarrow$ versus baseline \\
\hline
\end{tabular}




\begin{tabular}{|c|c|c|c|}
\hline Type of study & $\begin{array}{l}n=\text { no of subjects } \\
N=\text { no of studies }\end{array}$ & Serum zinc concentration & $\begin{array}{l}\text { Intracellular zinc } \\
\text { concentration }\end{array}$ \\
\hline Clinical Trial $^{27}$ & Metoprolol, 100 mg/day, 3 months $(n=22)$ & $\leftrightarrow$ versus baseline & $\leftrightarrow$ versus baseline \\
\hline Clinical Trial $\dagger^{28}$ & $\begin{array}{l}\text { Atenolol, } 50-150 \mathrm{mg} / \text { day, } \\
6 \text { months }(n=10)\end{array}$ & $\downarrow$ significant versus baseline & $\leftrightarrow$ versus baseline \\
\hline \multicolumn{4}{|l|}{ Statin therapy } \\
\hline Review 29 & $\begin{array}{l}\text { Statin therapy, various large scale studies } \\
N=29\end{array}$ & $\begin{array}{l}10-45 \% \text { increased relative risk for } \\
\text { type II diabetes (see above:**) }\end{array}$ & - \\
\hline Clinical Trial ${ }^{31}$ & $\begin{array}{l}\text { Simvastatin }(n=11) \text {, Atorvastatin }(n=9) \text {, } \\
10 \text { mg/day, } 4 \text { months }\end{array}$ & $\downarrow$ significant versus baseline & - \\
\hline
\end{tabular}

$\downarrow$ decreased, $\uparrow$ increased, $\leftrightarrow$ no change, - unreported data.

*Randomised clinical trial, dietary zinc intake controlled,

†Modified diet to improve lipid profile during test-period.

fDietary zinc intake monitored during test-period.

RBC, red blood cells; WBC, white blood cells.

Consequently, antiviral immune response diminishes. The frequently reported, yet unpublished, sudden worsening in COVID-19 disease could result from an abruptly depleted zinc-pool in already mild zinc deficient patients. In this respect, the loss of taste and smell, often reported by patients with COVID-19, ${ }^{36}{ }^{37}$ may be due to increased viral load. Yet, these are also known early symptoms of zinc deficiency. ${ }^{9} 1719243839$

\section{Nutritional and clinical aspects}

Foods abundant in zinc are fish, seafood, egg, meat, seeds, nuts, whole cereals and legumes. ${ }^{40}{ }^{41}$ In contrast, refined cereal products lack zinc. The bioavailability of zinc is higher when obtained from animal sources compared with vegetable sources and further depends on diet composition. A high dietary intake of phytates, certain fibres and lignin can bind zinc and therefore reduce zinc absorption. Phytates are more present in plant foods like unrefined cereal products and legumes. ${ }^{369}$ Besides, high calcium or iron intake may interfere with zinc absorption. ${ }^{6}{ }^{40}$ In addition, people with malabsorption as a result of gastrointestinal surgery, ${ }^{23}$ digestive disorders (like chronic diarrhoea, ulcerative colitis or Crohn's disease) or various other chronic illnesses are at risk of getting insufficient zinc. ${ }^{41}$

The recommended dietary allowance (RDA) of zinc for adults in Europe is $11 \mathrm{mg}$ /day for men and $8 \mathrm{mg} /$ day for women with a tolerable upper intake level (UL) of $40 \mathrm{mg} /$ day for both males and females. Different recommendations instead apply for children depending on their age: for ages $4-8$ years the RDA is $5 \mathrm{mg}$ /day (UL is $12 \mathrm{mg}$ /day), for ages $9-13$ years the RDA is $8 \mathrm{mg}$ /day ( $\mathrm{UL}=23 \mathrm{mg} /$ day) and for ages $14-18$ years the RDA is $11 \mathrm{mg} /$ day for males and $9 \mathrm{mg} /$ day for females (UL is $34 \mathrm{mg}$ /day for both sexes). ${ }^{5}$ Dosages considered as safe for oral supplementation in adults are between 10 and $12 \mathrm{mg} /$ day. Excessive dosages resulting in total daily dietary intakes reaching above the ULs, especially for prolonged periods of time, should be avoided. An overdose of zinc can induce copper deficiency and zinc accumulation has toxic effects. ${ }^{2610}$ Bioavailability of oral zinc supplements differs depending on their chemical composition. Zinc gluconate, citrate and picolinate are better absorbed compared with zinc oxide. ${ }^{40}$ Forms of zinc bound to amino acid compounds like aspartate, histidine and cysteine show higher bioavailability in comparison to zinc sulphate, chloride or acetate, with zinc oxide having the lowest uptake. ${ }^{6}$

Regarding interactions with medications, zinc supplements can interfere with the gastrointestinal absorption of tetracycline and quinolone antibiotics, inhibiting the absorption of both zinc and the antibiotic. Separating the moment of ingestion by taking the antibiotic at least 2 hours before or 4-6hours after taking the zinc supplement minimises this interaction. Zinc supplements can also reduce the absorption of penicillamine, an antirheumatic drug. Individuals can minimise this interaction by taking penicillamine at least 2 hours before or after ingestion of the zinc supplement. ${ }^{41}$ As far as can reasonably be ascertained, there are no other relevant effects of zinc on drugs.

Since zinc might decrease blood sugar in people with type 2 diabetes, it is important to monitor their blood sugar levels closely when starting zinc supplementation. The dose of diabetes medication might need adjustments. ${ }^{42}$

\section{Summary and conclusion}

Epidemiological research and observational studies provide indications for zinc depletion in high-risk groups for COVID-19. Various widely used hypotensive 
drugs and statins can affect zinc balance, worsening zinc homeostasis in already mild zinc-deficient individuals. As disturbed zinc homeostasis results in compromised immune functions, it is hypothesised to increase susceptibility for COVID-19. Therefore, correcting low zinc status in risk groups could play a pivotal role in preventing and controlling COVID-19 disease. Studies have shown that zinc depletion in hypertension can be corrected by dietary adjustments or zinc supplementation, ${ }^{43}{ }^{44}$ with the added benefit of improving glycaemic regulation and reducing inflammation. ${ }^{6} 4344$

In conclusion, there is an urgent need to implement dietary recommendations for all populations at risk of zinc depletion. In addition, prompt implementation of zinc supplementation should be considered in highrisk groups for zinc deficiency. These preventive and nutritional intervention measures have the potential to improve antiviral immune response for COVID-19 as well as for any future viral outbreaks. Large-scale studies are urgently needed to investigate the role of micronutrients in antiviral immunity, particularly drug-micronutrient immunity interaction.

Acknowledgements I would like to thank Nicolò Mossink and Luca Mossink for revising and improving this paper.

Contributors JM contributed to conceptualising and writing the manuscript.

Funding The authors have not declared a specific grant for this research from any funding agency in the public, commercial or not-for-profit sectors.

Competing interests None declared.

Patient consent for publication Not required.

Provenance and peer review Not commissioned; externally peer reviewed.

Open access This is an open access article distributed in accordance with the Creative Commons Attribution Non Commercial (CC BY-NC 4.0) license, which permits others to distribute, remix, adapt, build upon this work non-commercially, and license their derivative works on different terms, provided the original work is properly cited, appropriate credit is given, any changes made indicated, and the use is non-commercial. See: http://creativecommons.org/licenses/by-nc/4.0/.

\section{ORCID iD}

J P Mossink http://orcid.org/0000-0002-0576-1461

\section{REFERENCES}

1 Epidemiology Working Group for NCIP Epidemic Response, Chinese Center for Disease Control and Prevention. [The epidemiological characteristics of an outbreak of 2019 novel coronavirus diseases (COVID-19) in China]. Zhonghua Liu Xing Bing Xue Za Zhi 2020;41:145-51.

2 Read SA, Obeid S, Ahlenstiel C, et al. The role of zinc in antiviral immunity. Adv Nutr 2019;10:696-710.

3 Wessels I, Maywald M, Rink L. Zinc as a gatekeeper of immune function. Nutrients 2017:9:1286.

4 Haase H, Schomburg L. You'd Better Zinc-Trace Element Homeostasis in Infection and Inflammation. Nutrients 2078;2019:11.

5 Maggini S, Pierre A, Calder PC. Immune function and micronutrient requirements change over the life course. Nutrients 2018;10:1531.

6 Gammoh NZ, Rink L. Zinc in infection and inflammation. Nutrients 2017;9:624

7 Skalny AV, Rink L, Ajsuvakova OP, et al. Zinc and respiratory tract infections: perspectives for COVID-19 (review). Int J Mol Med 2020 doi:10.3892/ijmm.2020.4575. [Epub ahead of print: 14 Apr 2020].

8 Haase H, Rink L. The immune system and the impact of zinc during aging. Immun Ageing 2009;6:9.

9 Mocchegiani E, Romeo J, Malavolta M, et al. Zinc: dietary intake and impact of supplementation on immune function in elderly. Age 2013;35:839-60.
10 Mocchegiani E, Costarelli L, Giacconi R, et al. Micronutrientgene interactions related to inflammatory/immune response and antioxidant activity in ageing and inflammation. A systematic review. Mech Ageing Dev 2014;136-137:29-49.

11 Haase H, Mocchegiani E, Rink L. Correlation between zinc status and immune function in the elderly. Biogerontology 2006;7:421-8

12 Maywald M, Rink L. Zinc homeostasis and immunosenescence. J Trace Elem Med Biol 2015;29:24-30.

13 Barnett JB, Hamer DH, Meydani SN. Low zinc status: a new risk factor for pneumonia in the elderly? Nutr Rev 2010;68:30-7.

14 Lo Vecchio A, Dias JA, Berkley JA, et al. Comparison of recommendations in clinical practice guidelines for acute gastroenteritis in children. $J$ Pediatr Gastroenterol Nutr 2016;63:226-35.

15 Garg S, Kim L, Whitaker M, et al. Hospitalization Rates and Characteristics of Patients Hospitalized with Laboratory-Confirmed Coronavirus Disease 2019 - COVID-NET, 14 States, March 1-30, 2020. MMWR Morb Mortal Wkly Rep 2020;69:458-64.

16 Intensive Care National Audit \& Research Center. ICNARC report on COVID-19 in critical care 17 April 2020. Napier house 24 high Holborn London WC1V 6AZ, 2020. Available: https://www.icnarc.org/ Our-Audit/Audits/Cmp/Reports [Accessed 19 Apr 2020].

17 Kvamme J-M, Grønli O, Jacobsen BK, et al. Risk of malnutrition and zinc deficiency in community-living elderly men and women: the Tromsø study. Public Health Nutr 2015;18:1907-13.

18 Sanjeevi N, Freeland-Graves J, Beretvas SN, et al. Trace element status in type 2 diabetes: a meta-analysis. $J$ Clin Diagn Res 2018:12:OE01-8.

19 Król E, Bogdański P, Suliburska J, et al. The relationship between dietary, serum and hair levels of minerals ( $\mathrm{Fe}, \mathrm{Zn}, \mathrm{Cu}$ ) and glucose metabolism indices in obese type 2 diabetic patients. Biol Trace Elem Res 2019;189:34-44

20 Farooq DM, Alamri AF, Alwhahabi BK, et al. The status of zinc in type 2 diabetic patients and its association with glycemic control. J Family Community Med 2020;27:29.

21 Naik SK, Ramanand SJ, Ramanand JB. A medley correlation of serum zinc with glycemic parameters in T2DM patients. Indian $\mathrm{J}$ Endocrinol Metab 2019;23:188

22 Bandeira VdaS, Pires LV, Hashimoto LL, et al. Association of reduced zinc status with poor glycemic control in individuals with type 2 diabetes mellitus. Journal of Trace Elements in Medicine and Biology 2017;44:132-6.

23 Astrup A, Bügel S. Overfed but undernourished: recognizing nutritional inadequacies/deficiencies in patients with overweight or obesity. Int J Obes 2019;43:219-32.

24 Braun LA, Rosenfeldt F. Pharmaco-nutrient interactions - a systematic review of zinc and antihypertensive therapy: Pharmaconutrient interactions. International Journal of Clinical Practice 2013:67:717-25.

25 Suliburska J, Skrypnik K, Szulińska M, et al. Diuretics, CaAntagonists, and angiotensin-converting enzyme inhibitors affect zinc status in hypertensive patients on monotherapy: a randomized trial. Nutrients 2018;10:1284.

26 Cohen N, Golik A. Zinc balance and medications commonly used in the management of heart failure. Heart Fail Rev 2006;11:19-24.

27 Baykal Y, Yilmaz MI, Celik T, et al. Effects of antihypertensive agents, alpha receptor blockers, beta blockers, angiotensinconverting enzyme inhibitors, angiotensin receptor blockers and calcium channel blockers, on oxidative stress. J Hypertens 2003;21:1207-11.

28 Rubio-Luengo MA, Maldonado-Martín A, Gil-Extremera B, et al. Variations in magnesium and zinc in hypertensive patients receiving different treatments. Am J Hypertens 1995;8:689-95.

29 Yandrapalli S, Malik A, Guber K, et al. Statins and the potential for higher diabetes mellitus risk. Expert Rev Clin Pharmacol 2019;12:825-30.

30 Leonhardt W, Kurktschiev T, Meissner D, et al. Effects of fluvastatin therapy on lipids, antioxidants, oxidation of low density lipoproteins and trace metals. Eur J Clin Pharmacol 1997;53:65-9.

31 Ghayour-Mobarhan M, Lamb DJ, Taylor A, et al. Effect of statin therapy on serum trace element status in dyslipidaemic subjects. $J$ Trace Elem Med Biol 2005;19:61-7.

32 Prompetchara E, Ketloy C, Palaga T. Immune responses in COVID-19 and potential vaccines: lessons learned from SARS and MERS epidemic. Asian Pac J Allergy Immunol 2020;38:1-9.

33 te Velthuis AJW, van den Worm SHE, Sims AC, et al. Zn(2+) inhibits coronavirus and arterivirus RNA polymerase activity in vitro and zinc ionophores block the replication of these viruses in cell culture. PLOS Pathog 2010;6:e1001176.

34 Shittu MO, Afolami OI. Improving the efficacy of Chloroquine and Hydroxychloroquine against SARS-CoV-2 may require Zinc additives 
- A better synergy for future COVID-19 clinical trials. Infez Med 2020;28:192-7.

35 Han Y-S, Chang G-G, Juo C-G, et al. Papain-Like protease 2 (PLP2) from severe acute respiratory syndrome coronavirus (SARS-

CoV): expression, purification, characterization, and inhibition. Biochemistry 2005;44:10349-59.

36 Moein ST, Hashemian SMR, Mansourafshar B, et al. Smell dysfunction: a biomarker for COVID-19. Int Forum Allergy Rhinol 2020. doi:10.1002/alr.22587. [Epub ahead of print: 17 Apr 2020].

37 Lechien JR, Chiesa-Estomba CM, De Siati DR, et al. Olfactory and gustatory dysfunctions as a clinical presentation of mild-to-moderate forms of the coronavirus disease (COVID-19): a multicenter European study. Eur Arch Otorhinolaryngol;117.

38 Ueda C, Takaoka T, Sarukura N, et al. Zinc nutrition in healthy subjects and patients with taste impairment from the view point of zinc ingestion, serum zinc concentration and angiotensin converting enzyme activity. Auris Nasus Larynx 2006;33:283-8.

39 Pisano M, Hilas O. Zinc and taste disturbances in older adults: a review of the literature. Consult Pharm 2016;31:267-70.

40 Santos HO, Teixeira FJ, Schoenfeld BJ. Dietary vs. pharmacological doses of zinc: a clinical review. Clin Nutr 2020;39:1345-53.

41 Office of Dietary Supplements, National Institutes of Health $(\mathrm{NIH})$, U.S. Department of Health \& Human Services. Zinc: fact sheet for health professionals. Available: https://ods.od.nih.gov/factsheets/ Zinc-HealthProfessional/ [Accessed 12 May 2020].

42 MedlinePlus, National Library of Medicine, National Institutes of Health (NIH), U.S. Department of Health \& Human Services. Zinc, MedlinePlus (online health information resource), 2020. Available: https://medlineplus.gov/druginfo/natural/982.html [Accessed 12 May 2020].
43 Suliburska J, Bogdanski P, Szulinska M, et al. The influence of antihypertensive drugs on mineral status in hypertensive patients. Eur Rev Med Pharmacol Sci 2014;18:58-65.

44 Suliburska J, Skrypnik K, Szulińska M, et al. Effect of hypotensive therapy combined with modified diet or zinc supplementation on biochemical parameters and mineral status in hypertensive patients. J Trace Elem Med Biol 2018;47:140-8.

45 Marcellini F, Giuli C, Papa R, et al. Zinc status, psychological and nutritional assessment in old people recruited in five European countries: Zincage study. Biogerontology 2006;7:339-45.

46 du Preez MJ, Lockett CJ. Effect of clopamide, a thiazide diuretic, on copper and zinc levels in hypertensive patients. J Am Coll Nutr 1991;10:34-7.

47 Khedun SM, Naicker T, Maharaj B. Zinc, hydrochlorothiazide and sexual dysfunction. Cent Afr J Med 1995;41:312-5.

48 Golik A, Averbukh Z, Cohn M, et al. Effect of diuretics on captopril-induced urinary zinc excretion. Eur J Clin Pharmacol 1990;38:359-61.

49 Abu-Hamdan DK, Desai H, Sondheimer J, et al. Taste acuity and zinc metabolism in captopril-treated hypertensive male patients. Am J Hypertens 1988;1:303S-8.

50 Golik A, Modai D, Averbukh Z, et al. Zinc metabolism in patients treated with captopril versus enalapril. Metabolism 1990;39:665-7.

51 Golik A, Zaidenstein R, Dishi V, et al. Effects of captopril and enalapril on zinc metabolism in hypertensive patients. J Am Coll Nutr 1998;17:75-8.

52 Koren-Michowitz M, Dishy V, Zaidenstein R, et al. The effect of losartan and losartan/hydrochlorothiazide fixed-combination on magnesium, zinc, and nitric oxide metabolism in hypertensive patients: a prospective open-label study. Am J Hypertens 2005;18:358-63. 